\title{
COVID-19 Sürecinde Sağlık Sistemlerinin Zorlukların Üstesinden Gelebilme Kapasitesinin Geliştirilmesi ve Hemşireler ile Diğer Sağlık Profesyonellerinin Güçlendirilmesi \\ Enhancing the Capacity of Health Systems to Overcome Challenges and Strengthening Nurses and other Healthcare Professionals in COVID-19 Process
}

Füsun TERZiOĞLU

Atılım Üniversitesi, Sağlık Bilimleri Fakültesi, Türkiye

\begin{abstract}
öz
Günümüzde, lider ve yöneticiler tam anlamılla çözümü olmayan, kariyerlerini ve kurumlarının geleceğini tehdit eden, tarafların zarar görmesi kaçınımaz karmaşık birtakım problemlerle karşı karşıya kalmaktadırlar. Birbiriyle çelişen belirsiz bilgileri değerlendirirken yönetici ve liderin önceliği çoğunluğa en az zarar veren çözümü uygulamaya koymak olması gerekmektedir. COVID-19 gibi pandemiye neden olan ve yaşantılarımızı belirsizliğin hakimiyetine bırakan bir süreç eklenince hem kişisel hem de sağlık meslekleri olarak yönetmemiz gereken birden fazla kriz durumu ortaya çıkmıştır. Burada önemli olan husus, Quantum çağında karşllaştığımız bu olağanüstü durumları nası yönettiğimiz ve bu sürece nasıl liderlik ettiğimiz ile ilişkilidir.

Bu planlama sürecinde değișime nasıl ayak uyduracağımı ve nasıl liderlik edeceğimiz önemli bir konudur. Çünkü insanlar en önemli insan hakkı ve anayasal hakkı olan "yaşama hakkı" bağlamında bir riskle karşı karşııa kalmışlardır. Bu nedenle de bu süreçte kendimizi nasıl koruyacağımız ve nasıl sağılklı kalacağımız en önemli önceliklerimiz olmuştur. Sağlığın korunması ve güçlendirilmesi denince akla ilk gelen hiç kușkusuz bu konuyu kendisine mesleki ilke edinmiş olan sağlık profesyonelleridir. Sağlık profesyonellerine bu kriz yönetiminde, planlama, hız, uyum ve güven oluşturma açısından önemli sorumluluklar düșmektedir. Derleme tarzında hazırlanmış bu makalede COVID-19 sürecinde, yönetici ve liderlerin içinde bulundukları sağlık sisteminde zorlukların üstesinde gelebilme kapasitelerinin geliştirilmesi ile hemşirelerin ve sağllk profesyonellerinin güçlendirilmesi kapsamında yapılabilecekler tartışımıştır.
\end{abstract}

Anahtar Sözcükler: Covid-19, Hemşireler, Güçlendirme, Liderlik, Yönetim

\begin{abstract}
Nowadays, leaders and executives are faced with a complex set of problems that do not have a complete solution, threaten their career and the future of their institutions, and that the parties are harmed. When evaluating ambiguous information that contradicts each other, the priority of the manager and leader should be to implement the solution that gives the least harm to the majority. When a process such as COVID-19, which caused a pandemic and left our lives under uncertainty, more than one crisis situation emerged, which we had to manage both personally and as healthcare professionals. The important point here is related to how we manage and lead these extraordinary situations we encountered in the Quantum era.

How we keep pace with change and how we can lead this planning process is an important issue. Because people faced a risk in the context of the most important human right and constitutional right "right to live". Therefore, how to protect ourselves and stay healthy during this process have been our top priorities. The first thing that comes to mind when it comes to protecting and strengthening health is undoubtedly the health professionals who have adopted this
\end{abstract}

(1) TERZIOĞLU F: 0000-0002-4082-7059
Çıkar Çatışması / Conflict of Interest: Tüm yazarlar adına, ilgili yazar çıkar çatışması olmadığını belirtir.

Yazarların katkısı / Contribution of the Authors: TERZioĞLU F: Araştırma ve/veya makalenin hipotezini veya fikrini olușturan, Çalsşmanın bütününün veya önemli bölümlerinin yazımında sorumluluk almak

Atıf yazım sekli / How to cite : Terzioğlu F. COVID-19 Sürecinde Sağlık Sistemlerinin Zorlukların Üstesinden Gelebilme Kapasitesinin Geliștirilmesi ve Hemșireler ile Diğer Sağllik Profesyonellerinin Güçlendirilmesi. Türkiye Çocuk Hast Derg 2020; 14(suppl):76-83.
Yazışma Adresi / Correspondence Address:

Füsun TERZioĞLU

Atılım Üniversitesi Sağlık Bilimleri Fakültesi, Türkiye

E-posta: fusun.terzioglu@atilim.edu.tr
Geliş tarihi / Received : 06.05.2020 Kabul tarihi / Accepted : 22.07.2020 Elektronik yayın tarihi $\quad$ : 23.07.2020 Online published

DOI: 10.12956/tchd.733123 
issue as a professional principle. Health professionals have important responsibilities in planning this crisis in terms of planning, speed, compliance and trust. This article, prepared in a compilation style, discusses what can be done within the scope of the COVID-19 process, by improving the capacity of managers and leaders to overcome difficulties in the health system they are in and strengthening nurses and health professionals.

Key Words: Covid-19, Nurses, Empowerment, Leadership, Management

\section{GiRiş}

İnsanoğlu yeryüzünde var olduğu illk yillardan itibaren, doğal çevredeki olayların dışında her gün kendi yarattığı sürekli bir değișimi yaşamaktadır. Değișimin hızı asırlarla değil, saatlerle hatta dakikalarla ölçülür hale gelmiștir. Dünyanın neresinde olursanız olun, sağllk ve sağlık intiyaçlarının karşılanması, toplumsal kaygıların ve tartışmaların odak noktasıdır. Hatta sağ|lkla ilgili durumlar, çoğuzaman haberlere konu olabilmektedir. Bu durum, bazıları tahmin edilebilir, bazıları ise tahmin edilemez birkaç sebepten kaynaklanabilir ve global sağlik sistemlerinin kırılganlığı anlaşımışır. Aynı derecede diğer bir zorluk ise, pandemiye neden olan küresel sağlık krizleri ile karşı karşıya kalınmasıdır. Dünya Sağlık Örgütü (DSÖ)'ne göre pandemi olabilmesi için gerekli kriterler; toplumda daha önce görülmemiş bir hastalı̆̆ın ortaya çıkması, hastalı̆ın etkeni olan patojenin insanlara bulaşarak tehlikeli bir hastalığa yol açması ve hastalık etkeni patojenin insanlar arasında kolayca ve devamlı olarak yayılması yani bulașıcı olmasıdır. Bir hastalı̆ın pandemi olarakilan edilebilmesi için istikrarlı bir șekilde, dünyanın farklı noktalarında, kitleler üzerinde görülmeye bașlaması gerekmektedir ve DSÖ tarafindan ilan edilir. Dünyada illk pandemi nedeniyle karantina uygulanması 1377 yllında Dubrovnik ve Venedik'de cüzzam salgını nedeniyle olmuş ardından 300 yıl sonra ise Ingiltere'de veba salgını ile devam etmiștir. Pandemi tarihine baktığımızda bugüne kadar insanlığı etkileyen 21 pandemi meydana geldiğini, çok sayıda insanın ölümü ile sonuçlandığı ve dünyayı en çok etkileyen salgınlar arasında cüzzam, veba, kolera, grip, AIDS, SARS, Ebola ve günümüzde de COVID19 olarak gündeme gelmiştir. Bunlar içerisinde 2014'te Batı Afrika'da ortaya çıkan Ebola salgını, sağlığın korunması için global düzeyde ülkelerin harekete geçebilmesinin önemini göstermiştir. Enfeksiyonlarda, aynı insanlar gibi sınıları aşabilmekte ve dünyanın her bir köșesine yolculuk etmekte; doğal felaketler ve çatıșmalar ülke sınıı tanımamakta ve dünyadaki tüm ülkelerin sağlı̆ını etkilemektedir. Dünya sağı̆ğını etkileyen virüslere yönelik ortaya çıkan salgınlar ülkeler arasında hızlıca yayılabiliyor; hızlı ve etkin şekilde müdahale yeteneğine sahip bir sağlık sistemi yoksa çok büyük sorunlara yol açabiliyor $(1,2)$.

Coronavirusler, Corona viridae familyasına ait olan ve hem hayvanları hem de insanları enfekte eden bir virüs grubudur. Coronaviruslerin bazı türleri insanlarda soğuk algınlığına benzer hafif hastalıklara neden olurken, diğer türleri (MERS - Orta Doğu Solunum Sendromu ve SARS - Şiddetli Akut Solunum Sendromu gibi) daha ciddi hastallklara neden olabilmektedir. Daha önce insanlarda görülmemiş olan yeni bir coronavirus türü olan ve kısaca COVID-19 olarak adlandırılan coronavirus hastalığı ise Aralık 2019'da Çin'in Wuhan şehrinde ortaya çıkmıştır. Belirti ve bulguları arasında; başlangıç döneminde ateş, öksürük ve nefes darlığı, daha ciddi vakalarda ise pnömoni, ciddi akut solunum sendromu ve bazen de ölüm görülür (3). Günümüzde ortaya çıkan bu COVID-19 pandemisinden en çok etkilenen ülkelerde gördügümüz manzara, yetersiz sayıda sağlık çalışanına ve sağlık ekipmanlarına sahip sağlik sistemleri son derece kırılgan bir yapıya sahip olduğudur. Müdahalelerin zamanında yapılmaması, mevcut sağlık hizmetlerinin çökmesine, salgından etkilenen insanların tedavisinden sorumlu sağllk hizmeti çalıșanlarının hayatını kaybetmesine ve dolayısı ile de toplum sağlığının daha büyük tehditlere maruz kalabilmesine neden olmaktadır. Dünya Sağlık Örgütü (4). Ebola'dan etkilenen sağlık çalıșanlarının \%50'sinden fazlasının hemşire ve hemşire yardımcısı olduğu ve virüsten etkilenen sağlık çalışanlarının üçte ikisinin hayatını kaybettiği belirtmiștir $(5,6)$.

COVID 19 sürecinde de pek çok sağlık çalıșanının hem kendisi hem de aile ve yakınları etkilenmiş, hayatını kaybetmiş ve etkilenmeye de devam etmektedir. Sağlık çalışanlarının COVID-19 enfeksiyonundan etkin șekilde korunabilmeleri için, etkeni iyi tanımaları, nası, nerede, ne șekilde bulaș riskinin arttığını bilmeleri ve uygulamaları gereken korunma önlemlerinin farkında olmaları gereklidir. Sınırlı sayıda yayın sağlık çalıșanları arasındaki enfeksiyon için risk faktörleri belirlemiştir. Ön sonuçlar, sağlık çalışanlarının hem işyerinde hem de toplumda, çoğunlukla enfekte aile üyeleri aracilığılla virüsü aldıklarını göstermektedir (7). 10 Nisan 2020 tarihli bir durum raporunda, 15.334 sağlık çalışanının hastalığa yakalandığı, bu sayının toplam vaka sayısının \%11'ini oluşturduğu belirtilmiştir (8). Sağlık çalışanlarında COVID-19 enfeksiyonunun görülmesi ile ilişkili olarak hastalarda COVID-19 tanısının erken dönemde konamaması, yüksek riskli bir bölümde çalsşma, uzun çalısma saatleri, uygun olmayan el hijyeni uygulamaları gibi enfeksiyon önleme ve kontrol önlemlerine yeterli düzeyde uyulmaması ve kișisel koruyucu donanımların (KKD) eksikliği veya uygunsuz kullanımı gibi faktörler üzerinde durulmaktadır $(9,10)$. COVID-19 virüsü dahil solunum patojenleri için eksik veya yetersiz enfeksiyon önleme ve kontrol eğitimi ve çok sayıda COVID-19 hastasının bakımının yapıldığı alanlarda uzun süre zaman geçirme gibi bașka faktörler de bildirilmiștir. COVID-19 hastalarının bakımında ve tedavisinde görev alan sağlık çalışanları, normalden daha uzun süre çalıştıkları, kendi aile üyelerine hastalı̆ı bulaştırma endişesi ile onlardan uzak kaldıkları, yoruldukları, tükendikleri, damgalanmaya, fiziksel ve psikolojik șiddete maruz kaldıkları için, onların fiziksel ve zihinsel sağlığının korunması ve sürdürülmesi için çaba sarf edilmesi önemlidir. Bu nedenle DSÖ, tükenmișlik riskinin azaltıması, güvenli ve sağ|ıklı çalıșma ortamlarının olușturulması ve sağllk çalışanlarının iyi çalışma koşullarında istihdam edilme haklarına 
saygı duyulması için enfeksiyon önleme ve kontrol önlemlerinin, iş sağlığı ve güvenliği önlemlerinin alınmasını ve psiko-sosyal desteğin, yeterli nitelik ve nicelikte personelin istihdam edilmesini ve klinik rotasyon yönteminin uygulanmasını önermektedir (11).

Bu salgın birçok soru işaretini de beraberinde getirmiştir. Hastalıktan veya ölümden kaynaklanan sağlık hizmeti çalışanı eksikliğine nasıl hızlı şekilde müdahale edilebilir? Hemşire ve diğer sağlık profesyonelini iş gücünü farklı alanlarda hizmet verebilmeleri için nasıl çabucak eğitebiliriz? Doğru ekipmana hızlı şekilde nasıl ulaşabiliriz? Toplum ile etkin şekilde nasıl iletişime geçebiliriz? Bu tarz krizlere zamanında ve etkin şekilde müdahale edebilirken aynı zamanda da gerekli temel sağlık hizmetlerini sağlamaya devam eden sağlık sistemlerine intiyacımız olduğu ortadır. Bir sağlık sisteminin zorlukların üstesinden gelebilme kapasitesi, çatışma, doğal afet ve bir hastalığın aniden yayılması gibi kriz durumlarına maruz kalındığında cevap verebilme, uyum sağlayabilme ve güçlenebilme kapasitesine bağlıdır (12, 13). Sağlık sisteminin zorlukların üstesinden gelme kapasitesi, sağlık sistemi Öznelerinin, kurumların ve ülke nüfusunun ,krizlere verimli şekilde tepki verebilmesi ve bunlara hazır olması, krizle karşılaşıldığında sistemin ana fonksiyonlarını devam ettirebilmesi, kriz sırasında öğrenilenlerden ders çıkarabilmesi ve eğer koşullar gerektiriyorsa baştan organize edilebilmeleri anlamına gelmektedir $(14,15)$.

"Küresel Sağlık 2035: Tek kuşakta birleşen Dünya" isimli Lancet Komisyon raporunda, sağlığa yapılan yatırımların ne kadar önemli olduğu belirtilmektedir. Rapor, sağık teknolojilerinin seviyesini yükseltecek ve dağıtım sistemlerini iyileştirecek gelişmiş yatırımlar ile anne-çocuk ölüm oranlarının yanı sıra bulaşıcı hastalıklardan kaynaklanan ölüm oranlarının da evrensel düzeyde düşük seviyelere çekilebileceğini gösteren ayrıntılı bir analiz sunmaktadır. "Birleșmenin sağlanması durumunda 2035'te alt ve alt-orta gelir seviyesindeki ülkelerde 10 milyona yakın ölümü önlenebileceği öngörülmektedir (16).

Zorlukların derecesi ne olursa olsun, herkese her yaşta sağlıklı yașam ve iyi olma durumu sağlamaya odaklanmanın sürdürülebilir gelișmenin esaslarından olduğu, günümüzde küresel düzeyde kabul görmektedir. Güçlü, zorlukların üstesinden gelebilen ve hızlı değişimlere anında cevap verebilen sağlık sistemlerine olan intiyaç, Birleşmiş Milletler Sürdürülebilir Kalkınma Hedefleri (SKH'ler)'nin tam kalbinde yer almaktadır. SKH Hedef 3'de, her yaştan herkese sağlıklı yaşam sağlamak ve sağlıklı olmayı teşvik etmek, diğer sürdürülebilir kalkınma hedeflerine ulaşmanın temelini oluşturuyor. Evrensel Sağlık Güvencesi sadece ihtiyacı olanlara sağlık hizmetlerini ulaştırmayı değil, insan merkezli kaliteli sağlık hizmetlerinin sunulmasını amaçıyor. Bu, yeterli sayıda iyi eğitilmiş ve istekli sağlık çalışanına sahip iyi ișleyen bir sağlık sistemini gerektirmektedir. 2030'da yaklaşık 10.1 milyon sağlık çalışanı (hemşireler, ebeler, hekim ) açığı olacağı öngörülmektedir (17). Binyıl Kalkınma Hedefleri'ne ulaşmada zorluk yaşayan ülkelerin çoğu, sağlık iş gücü eksikliği ve bu iş gücünün yanlış dağıtımından muzdarip olmaktadır. Hemşirelerin de dahil olduğu kalifiye sağlık personelinin azlığı, etkin sağlık sistemine ulaşmadaki en büyük engellerden biri olarak görülmektedir (18).

Bu nedenle, Dünya Sağlık Örgütü, Sağlık'ta İnsan Kaynakları üzerine Küresel Strateji ( HRH ): İş Gücü 2030'u geliştirmiştir. Tüm sağlık çalışanlarının, güvenli ve insancıl yaşam koşullarına sahip olmaları ve her türlü baskı ve şiddetten korunması gerektiği vurgulanmıştır. Sağlık sistemlerini güçlendirmede ve bunların zorlukların üstesinden gelme kapasitelerinin arttırılmasında toplumsal sağlığın rolünün tüm hemşireler ve diğer sağlık çalışanları için bir öncelik olduğu açıktır. Sağlığın geliştirilmesine, hastalık ve rahatsızlıkların önlenmesine yatırım yapılması; kişilerin sağlıksız duruma geçmeleri ile sağlık sistemi üzerinde yaratacakları talebi ortadan kaldırarak ve sağlıkı ve üretken kalan vatandaşların topluma yapacakları ekonomik katkı ile pozitif bir etki yaratabilir $(16,19)$. Sürdürülebilir Kalkınma Hedefleri ve Sağlıkta İnsan kaynakları önerilerinde yer alan, karar almaya dair bütün tavsiyeler, sağlığın sosyal belirleyenleri üzerinde yapılacak çalışmaların, uzun vadede klinik sonuçları iyileştirmesi, para ve zaman tasarrufu sağlaması sebebiyle, sağlık çalışanlarının işinin merkezi bir parçası olması gerektiğini söylüyor.

Günümüzde sağlık profesyonellerinin ve özellikle 24 saat kesintisiz hizmet veren hemşirelerin günlük uygulamalarında, güçlü sistemlerin oluşturulması yolunda ciddi bir role sahip oldukları açıktır. Sağlıklı yaşamı ve sağlıklı olmayı teşvik etmenin özünde bütün hemşireler için yatan temel prensip, sosyal adalet kavramıdır. Sosyal adalet kavramı sağlığa ve sağlık güvencesine uygulandığında, sağlık hizmetlerine erişimden daha fazlasına işaret ederek; ayrıca, barınma, gıda güvencesi, ulașım, çalışabilme ve eğitime erişim anlamına da gelmektedir. Sosyal adalet için harekete geçmek, farklılıkları azaltmak ve eşit erişim imkânını yaymak anlamına gelir (20-22).

Dünya Sağlık Örgütü, 6 temel ilkeye tekabül eden 6 ana alanda uzun vadeli yatırım yapılmasını önermektedir.

1. Yeterli sayıda eğitilmiş sağlık çalışanı

2. Illaçlara ve gerekli tıbbi malzemelere ulaşabilme

3. Denetimleri ve izlemeyi de içeren güçlü sağlık bilgi sistemleri

4. Uygun altyapı oluşturma

5. Yeterli kamusal finansman

6. Eşit ve kaliteli hizmet sağlayacak güçlü bir kamu sektörü

Sonuç olarak, sağlık sisteminin zorlukların üstesinden gelme kapasitesi, sağlık sistemi öznelerinin, kurumların ve ülke nüfusunun krizlere verimli şekilde tepki verebilmesi ve bunlara hazır olması, krizle karşılașıldığında sistemin fonksiyonlarını devam ettirebilmesi, kriz sırasında öğrenilenlerden ders çıkarabilmesi ve eğer koşullar gerektiriyorsa baştan organize edebilmeleri anlamına gelmektedir.

\section{Sağlık Sistemlerinin COVID 19 Sürecinde Başarması Gereken Hedefler}

Panter-Brick (23), "Sağlık söz konusu olduğunda, risk üzerine yapılan araştırmalar, zorlukların üstesinden gelebilme kapasitesi 
üzerine yapılan araştırmalara göre genellikle baskın çıkığını ifade etmiştir. Ancak, sağlık araştırmaları ve uygulamalarında, dikkati riskten alıp zorlukların üstesinden gelebilme kapasitesine doğru çeken ve gittikçe büyüyen bir momentum söz konusudur (23).

Giderek artan bir şekilde kanıtlar, organizasyonun zorlukların üstesinden gelebilme kapasitesi ile organizasyonun çıktılarını birbirine bağlayan güçlü bir bağ olduğunu göstermektedir. Organizasyonun zorlukların üstesinden gelebilme kapasitesini geliştirmeyi destekleyen pozitif stratejiler içinde işten kaçınma ve işi başkasına yıkmanın azalması, sağlıklı olmanın gelişmesi ve üretkenliğin artması gibi çok önemli kişisel ve organizasyonel faydaları olan sonuçlar bulunmaktadır (24). Risk yönetimi, risklerin belirlenmesi, analiz edilmesi ve yönetilmesidir. Basit haliyle, hangi olayların (tehlikeler) gelecekte zarara yol açabileceğini belirlemek ve bu olayların gerçekleşme intimalini (Ne sıklıkta?) ve olası sonuçlarını (ne kadar kötü?) minimize etmektedir (25).

Başarılı sağlık sistemlerinin hedefi, uyum sağlayabilme, öğrenebilme ve esnek olabilmektir. Bu üç ana konsept, zorlukların üstesinden gelebilme kapasitesini oluşturma ve geliştirmede temel etkenlerdir.

- Esneklik; organizasyonun kolay bir şekilde işleyişini değiştirebilme yeteneğidir. İşleyiş ise; iş gücü istihdamı veya hizmet ulaştırma modelleridir.

- Uyum sağlayabilme; bir organizasyonun belli durumlara uyum sağlayabilmesi veya belli bir amaç için daha iyi çalışabilmesi yeteneğidir.

- Öğrenebilme; öğrenebilen bir organizasyon üyelerinin öğrenme süreçlerini teşvik edebilen ve sürekli olarak kendini değiştirebilen organizasyondur

Kruk ve ark. (14), zorlukların üstesinden gelme kapasitesine sahip bir sağlık sisteminin 5 ana unsurunu tanımlamıştır:

\section{Zorlukların üstesinden gelebilme kapasitesine sahip sistemlerde farkındalık vardır: Bu sistemler bilgiyi, risk} ve müdahaleleri anlamak ve modellemek için kullanırlar

2. Zorlukların üstesinden gelebilme kapasitesine sahip sistemlerde kapsamlılı vardır: Ana sağlık hizmeti, iş gücü kapasitesi gibi birçok çeşitli kaynağı kullanarak geniş alana yayılmış zorlukları tespit edip, bunların üstüne gidebilirler.

3. Zorlukların üstesinden gelebilme kapasitesine sahip sistemler kendi kendilerini düzenler: Tehlikeleri tespit edip, onları izole edebilir ve bunu yaparken hala temel sağlık hizmetlerini sunabilir ve gerektiğinde ek kaynaklar oluşturabilir

4. Zorlukların üstesinden gelebilme kapasitesine sahip sistemler bütünleşik sistemlerdir: Temel ortaklar, topluluklar ve kurumlar ile güçlü bağlar kurarlar.

5. Zorlukların üstesinden gelebilme kapasitesine sahip sistemler uyum sağlayabilen sistemlerdir: Sadece kriz dönemlerinde değil, normal zamanlarda da demografik intiyaçlara göre, ülke içinde yer değiştiren insanlara ve hizmeti ulaştırma yöntemlerine göre kendilerini değiştirebilirler.

Tüm bunlar, zorlukların üstesinden gelebilme kapasitesine sahip sağlık sistemlerinin oluşturulması için ayrılmış sınırlı kaynakları nereye yatırmalı sorusunu gündeme getirmektedir. Unutulmamalıdır ki temel sağlık hizmeti, devletlerin ve toplumların karşılayabildiği maliyetlerde insanlara temel sağlık hizmetlerini ulaştırmanın verimli ve tercih edilen yoludur (26). Bir ulusal sağlık sistemi; insanlarına, bir dizi kamu tarafından fonlanmış, temel, herkes tarafından ulaşılabilir ve adil sağlık hizmetleri sunan bir temel sağlık hizmeti üzerine kurulduğunda, daha verimli hale gelmektedir (27). Finansman mekanizmaları yoksul insanların üzerinde ağır bir yük bindirmeden sağlık hizmetine herkesin ulaşabilmesini sağlamalıdır. Bu ise kaliteli sağlık hizmetine ulaşmanın önündeki, direkt cepten ödeme, sağlık kuruluşuna ulaşmada kat edilen fiziksel mesafe ve harcanan zaman gibi sağlık hizmetine ulașmayı engelleyen bariyerleri ortadan kaldıran etkili bir finansman modeli gerektiriyor (28).

COVID 19 gibi bulașıcı hastalıkların patlak vermesine etkili bir şekilde müdahale edebilmek için zorlukların üstesinden gelebilen sağlık sistemlerine, -uyumlu, bilinçli ve bütünleşik sistemlere- intiyacı vardır. Zorlukların üstesinden gelebilen sağlık sistemlerine yapılan yatırım küresel kamu yararı ve herkesin ortak çıkarı için yapılmış bir yardım olarak görülmelidir (11). Zorlukların üstesinden gelebilme kapasitesini geliştirmeye dair CIPD'nin hazırladığı rehber, bireylerin zorlukların üstesinden gelebilme yeteneği geliştirebilmeleri için uygulayabilecekleri üç yaklaşımı tanımlamıştır. Bu yaklaşımlar, odaklandıkları yere,- bireyin kendi niteliklerine, sosyal çevresine ya da her ikisinin birleşimine- göre belli başlıklarda toplanabilir (29):

1. Kişilik/Bireysel Nitelikler: Zorlukların üstesinden gelebilme yeteneği kişiye özeldir ve bireyin kişiliğinin bir parçasını oluşturan içsel bir yetenek olarak görülür. Ve bu kontrolün bireyde edindiği yeri (kişinin hayatı üzerindeki kontrolü), kișinin tahammül sınırını, duygularına dair farkındalığını ve bunları yönetimini, iyimserliğini, perspektifini, espri anlayışını, Öz yeterliliğini ( kişinin becerilerine olan inancı), ve problem çözebilme yeteneğini içerebilir.

2. Çevre: Zorlukların üzerinden gelebilme yeteneği tamamen kişinin çevresi ile girdiği etkileşimlere bağlıdır. Yani ne kadar sosyal destek aldığı gibi, kişinin elinde olmayan faktörler, kişinin zorlukların üstesinden gelebilme yeteneğinin seviyesini belirler. Bireyin kişiliği ise konuyla alakalı gözükmemektedir.

3. Kişi-Çevre: Zorlukların üstesinden gelebilme yeteneği; bireyin kişiliğinin, ailesi, yakınları ve sosyal çevresi gibi çevresel etkileyenler ile kombine edilmesinin bir ürünüdür.

Sull ve ark. (30) çalışanların iyiliğinin önemine ve hasta bakımındaki etkisine dayanarak, organizasyonların iş yerinde, 
kişilere zorlukların üstesinden gelebilme yeteneğini öğreten girişimleri desteklemeleri için güçlü bir neden olduğunu belirtmektedir. İngiltere'de bulunan NHS Health and Wellbeing Review hasta bakımının etkinliği; hastaların deneyimleri, hasta güvenliği ve çalışanların sağlığı ve iyi olma durumları ile bağlantıı olduğu vurgulanmışıır (31). Bütün ulusal ve uluslararası sağlık organizasyonlarının gelecek için açık bir strateji ve vizyon geliştirmeleri gereklidir.

\section{Zorlukların Üstesinden Gelebilme Yeteneği Üzerine Robertson Cooper Modeli (32; 33)}

Küresel düzeyde pandemiye yol açan durumlarda, kişilerin bu süreçte zorlukların üstesinden gelebilmeleri için Robertson Cooper Modeli geliștirilmiştir. Bu model, COVID-19 sürecinde de kolaylıkla uygulanabilir.

Güven: Yetkinlik hissi, stresli durumlar ile mücadele etme etkinliği ve güçlü bir özgüven zorlukların üzerinden gelinebileceğinin hissedilmesinin özünde yer alır. Bireylerin ne arallılarla pozitif ve negatif duygulara maruz kaldıkları da ayrıca önemlidir.

Amaç Sahibi olmak: Net bir amaç sahibi olma hissi, kişi için net olan değerlere sahip olmak, sahip oldukları istikamet ve yön kişilerin olumsuzluklar ile karşılaştıklarında mücadeleyi bırakmamalarını ve bunların üstesinden gelebilmelerini sağlamaktadır.

Sosyal destek Zorluklarla tek başlarına mücadele etmek yerine diğer insanlar ile iyi ilişkiler kurmak ve yardım istemek kișilerin olumsuz durumlardan daha kolay kurtulmalarını sağlar.

Uyum sağlayabilmek: Kendi elimizde olmayan durumlara uyum sağlamak ve esnek olabilmek zorlukların üstesinden gelebilme yeteneğine sahip olmada olmazsa olmazdır. Zorlukların üstesinden gelebilen bireyler değişiklikler ile daha iyi başa çıkarlar ve durumdan etkilenmeden önceki hallerine daha çabuk dönerler.

Refah uzmanları, Robertson Cooper'ın; kişinin zorlukların üstesinden gelebilme yeteneğini, yaşanılan tersliklerin etkili şekilde geride bırakılmasını da içeren, iş performanslarını ve iyi olma durumlarını baskı altında da devam ettirebilme kapasitesi olarak tanımlıyor. Bu uzmanlar, zorlukların üstesinden gelebilme yeteneğini güçlendirmede kullanılan eğitici ve geliştirici yaklaşımları desteklemekte kullanılan bir model hazırladılar. Kișinin bașlangıç noktası ne olursa olsun zorlukların üstesinden gelebilme yeteneğinin pozitif șekilde geliștirilebileceği fikri de yine bu uzmanlara aittir.

Bu görüş ayrıca, Jackson ve ark. (34) yaptığı, sağllk profesyonellerinin özellikle de hemşirelerin zorlukların üstesinden gelebilme yeteneklerini geliştirerek ve güçlendirerek iş yerlerinde karşılaştıkları zorluklara olan kırılganlıklarını azaltabileceklerini öneren araștırma ile desteklenmiștir. Zorlukların üstesinden gelebilme yeteneği eğitimlerinin hemşirelik eğitiminde yer alması ve mentörlük programları araclığı ile profesyonel desteğin sağlanması gittikçe artan șekilde önerilmektedir.

\section{Sağlık Profesyonellerinin COVID 19 Sürecinde Zorlukların Üstesinden Gelebilme Yeteneğinin}

Güçlendirilmesi: Sağlık profesyonellerinin zorlukların üstesinden gelebilme yeteneği ve sağlik hizmeti sağlayabilme yeteneği arasındaki ilişkinin anlaşıması önemlidir. Kriz durumlarında yaşanan toplumsal şokun kişiler arası şiddet ve intihar risklerini potansiyel olarak artırdığını ve kişilerin refahı ve akıl sağlığı üzerinde anında etki gösterdiğini biliyoruz. İşsizlik akıl sağlığı için temel risk faktörlerinden biridir. Küresel düzeyde, üretkenliğin kaybolması, yılların işsizlikle geçmesi majör depresif bozuklukların en önemli ikinci nedenidir (35).

lyi bir çalışma ortamı, fiziksel ve akıl sağlığı açısından önemlidir. Çalsşma ortamındaki bazı stres faktörleri ve yüksek beklenti seviyeleri çalsşanları olumsuz olarak etkileyebilmektedir (34). Sağlık çalışanlarının işverenlerinin, sistemdeki en iyi uygulamaları modellemede liderlik rolünü üstlenmelerini bekleyebiliriz. Meslek uygulamalarındaki değișiklikler, yeniden yapılandırma ve sorumluluklardaki hızlı değișimleri; psikolojik stres, fiziksel tükenme, moral bozukluğu, çökkünlük hissi ve depresif bozuklukların görülme intimalini arttırabilir.

Sağlık profesyonellerinin ve hemșirelerin sağllk sistemlerini güçlendirmede ve zorlukların üstesinden gelebilme kapasitesini geliştirmede katkıları tartışılmazdır (36). Sağlık profesyonellerı içinde hemşirelerin dönüştürücü değişikliklerin lokomotifi oldukları birçok örnek bulunmaktadır; hemşireler, karar almadan uygulamaya kadar sistemin bütün kademelerinde birçok hizmetin insanlara ulaștııılmasındaki önemli aktivitelere liderlik etmektedirler. Bu nedenle sorumlulukları süreklilik arz etmektedir. Bu pandemi döneminde yeni beklentilere yönelik gerekli yeni yeteneklerini geliștirmeleri gereken üç öncelikli alan bulunmaktadır. Hemşireler ve diğer sağlık profesyonelleri etkilerini ve değişimin hızını artırmak için; merkezde yer almalı, esnek, uyum sağlayabilen ve yeni öğrenme biçimlerine açık bireyler olmalıdıllar. Bu üç alan aşağıda belirtilmiştir:

1. Sağlık Profesyonelleri ve Hemşirelerin dijital teknolojilerin uygulanması ile ilgili rolü,

2. Kaliteyi ve etkiyi gösterebilme gücü

3. Sistem liderliği

\section{Dijital Teknolojilerin Uygulanması}

Dünya Sağlık Örgütü'nün açıkladığı güçlü bir sağlık sistemi için gerekli 6 temel ilkede bahsettiği üzere iyi çalışan bilgi sistemlerine intiyaç var ve bu hedefe ulașmak için hemșireler uygun șekilde donatılmalılar. Sağlık hizmeti sistemleri ve iletișim teknolojilerinde gerçekleşen hızı değişiklikler arasındaki bağlantı sağılı hizmeti yeniliklerinin daha önce hiç olmadığı kadar hızlı gelişmesini ve yayılmasını sağlamaktadır. Hemşireler, uzman danıșmanlığının daha çok insana ulașmasını sağlamak için teknolojiyi kullanarak uzak mesafelerdeki temel sağlık hizmeti ünitelerine bağlanabilmelidir. Günlük rutinlerinin içeriğinde hemşireler, teknolojiyi yașamsal belirtileri gözlemlemek, ilaçları insana ulaștırmak ve sonuçları ölçmek için kullanmaktadır. Dijital 
yöntemleri kullanmak, sağlık hizmetlerini ulaştırma şeklinin tamamen baştan ele alınması ve yeni fırsatların olduğu yerleri kavramaları gerekmektedir. Küresel düzeyde sağlık hizmetlerine her yıl 4 trilyon dolar harcıyoruz, ancak bunun çok az bir miktarı sağlık hizmetlerini dönüştürmek için digital teknolojiyi kullanılabilir hale getirmeye gidiyor. Elbette bu tek başına bir çözüm değil ve daha geniş bir değişim kültürü içine yedirilmediği sürece, etkisi de kayda değer olmayacaktır (37).

Hemşireler ve diğer sağlık profesyonelleri teknolojik sistemin liderleri olmalı ve teknolojinin, kaliteyi ve hasta güvenliğini geliştireceğini ve sağlik hizmeti yöntemlerini kökten değiştirebileceğini kabul eden bir anlayış geliştirmeli ve teşvik etmelidir. Dijital teknoloji, her klinik ortamda hemşireliğin ve diğer sağllk profesyonellerinin yer aldığı aşamaların her birisini etkilemektedir ve bu zorlu görevi üstlenecek liderlere sahip olunmalıdır. Cooper'ın belirttiği gibi "Teknolojiden ve bilgiden fayda sağlayabilmek, eğitimi, stratejik planlamayı ve çalışma şeklimizi geliştirmek için sağlık verilerinin iyi kullanılması gerekmektedir" (38).

Hemşirelerin bilgisayar ve bilgi teknolojilerine hazır oluş düzeyi hemşirelik bilişimi ve bilgi sistemlerinin gelişiminde önemli bir etmendir. Hemşireler hastanın gereksinimlerini belirleyerek, doğrudan bakım veren, verdiği bakımın sürekliliğini izleyen ve kayıt eden sağllik ekibinin önemli bir üyesi olarak sağlik bakım sisteminde önemi hızla artan teknolojinin en önemli kullanıcılarındandır. Hizmet ve uygulama alanlarında görev alan hemşirelerin bilgi gereksinimini fark etme, gereksinim duyulan bilgiye ulaşma, bu bilgiyi etkin kullanma, değerlendirme ve sunma olarak tanımlanan, bilgisayar okuryazarlığını da içine alan bilgi okuryazarlığı becerisine sahip olmasını gerektirmektedir.

\section{Kaliteyi ve Etkiyi Gösterebilme}

Sağlam bir bilgi altyapısı (yani dijital teknoloji) ikinci öncelik alanı için bir ön koşuldur. Hemşirelerin yaptıkları işlerin kalitesini ve etkilerini ne derece gösterebildikleri, sistemin geri kalanının hemşirelerin sahip olduğu rolü anlamasını ve buna değer vermesini sağlamada önemli bir noktadır. Kaliteyi ve etkiyi gösterebilmek, zorlukların üstesinden gelebilme kapasitesini geliştirmek adına ortaya koyulan hemşirelik katkılarının optimize edilmesi için gereken kaynakların ve çevrelerin harekete geçirilmesini sağlayacaktır (39). Hemşirelerin yaptıkları işler genellikle diğer insanlara görünmez gelir ve teknolojinin hizmetin eşiğinde kullanılması bu işlerin görünürlüğünü arttırabilir. Ancak, hemşirelerin kalite standartlarının geliştirilmesinde aktif şekilde yer almaları, karar alma ve sistem kademelerinin değişiklikleri üzerinde etkili olabilmek için daha geniş fırsatlara sahip olmaları birinci derece önemlidir. Bu durum kalite ve insan merkezleri sistemleri üzerine hemşirelik uzmanlığının etkisinin daha büyük olmasını sağlayacaktır. Hemşirelik uzmanlığı, hükümet ve karar alma mekanizmalarının her kademesinde görünür olmalı ve sağllk sistemi içinde kaliteli sağllk hizmetinin vatandaşlara ulaşmasında sahip olduğu önemli rol sebebiyle değer görmelidir.

\section{Sistem Liderliği}

Liderliğin doğası, hemşirelik ve sağllk hizmeti için önemi hakkında çok fazla şey yazıımıştır (40). Ancak daha önce tanımladığımız gibi; günümüzün hemşire liderleri, kendilerini atik ve esnek yöntemlerle çalışmaya zorlayan birçok öngörülen ve öngörülmeyen zorluk ve değişiklikle yüzleşmektedirler.

Hiyerarşik organizasyon yapısıla bağlantılı olan tek bir organizasyonel modeli temel alan klasik liderlik modelleri sürdürülemez hale gelecektir. Özellikle kamu sektörlü liderliğinde; hizmetler bütünleşmiş oldukça, hizmet yöntemler dönüştükçe, kaynaklar paylaşıldıkça ve personel çok farklı yöntemler aracılığı ile görevlendirildikçe organizasyonel, mesleki ve coğrafi sınılarda bulanıklaşma görülmeye başlandı (36, 41, 42). Fillingham ve Weir (43)“ Bütün liderlerin ağırlık merkezlerinin artık organizasyonlarına olan bağllıktan, vatandaşa ve daha geniş bir nüfusa olan bağllığa kayması gerektiğini” önermektedir (s.23). Bu, paylaşılan vizyon ve birlikte çözüm üretiminin altını çizen bir niteliktir.

Fillingham ve Weir (43) "Sistem Liderliği" diye bir yaklaşım tanımlıyorlar. Bu yaklaşım iki ayrı ve aynı zamanda birbiriyle alakalı özellik tarafından karakterize edilebilir; i) iş birliği ii) sınıların aşılması - organizasyonel, mesleki ve kişisel böylece liderler olağan sorumluluk ve yetkilerinin sınılarının ötesine geçebilecekler.

\section{Bireysel Olarak Hemşirelerin ve Diğer Sağlık Profesyonellerinin yapması gerekenler (44-47):}

- Sağlığınızı ve iyi olma durumunuzu koruyun

- Zorlukların üstesinden gelebilme yeteneğinizi geliştirmeyi öncelik haline getirin ve iş arkadaşlarınızın da bu özelliklerini geliştirmelerine destek olun

- Bireysel bakımlarını üstlenebilme yeteneklerini geliştirme anlayışına sahip olabilmeleri için hastalar, bakıcılar ve topluluklar aktif şekilde çalışabileceğiniz yollar arayın

- Hizmet kalitesi yüksek hemşirelik uygulamalarının hasta sonuçların üzerindeki pozitif etkisini gösterebilmek için becerilerinizi geliştirin

- Sağlık sistemi üzerine fikir üretme yönteminizi sistem içinde güçlü birliktelikler kurarak geliştirin

\section{Kurumlar/iş verenler}

- Sağlık hizmeti çalısanları için Pozitif Çalışma Ortamını sağlayın

- Sağlık hizmeti çalışanlarının sağlık ve refahını destekleyin

- Çalışanlara öğrenme firsatları sunun

- Kritik vaka değerlendirmesinin organizasyon içinde var olmasını sağlayın

- Afet planlanmalarını yapın

\section{Karar Alıcılar}

- Pozitif Çalışma Ortamını sağlayan ve sağlık hizmeti çalışanlarını koruyan yasaları çıkarın ve uygulayın 
- Sağlik hizmeti iş gücünü uygun şekilde planlayın ve yönetin. Ulusal düzeyde sağlıkta insan kaynakları planı oluşturun ve etkin şekilde uygulayın

- Hastalık odaklı sistemden önleyici sağlık hizmeti ve sağlıklı olmayı teşvik etme anlayışına geçişi hızlandırın

- Zorlukların üstesinden gelebilme planlamasının sağlık sisteminin stratejik gelişmesinin bir parçası olmasını sağlayın

- Hemşirelik becerilerinin sistem içerisinde optimal kullanımı için hemşirelerin karar alma mekanizmalarında yer almalarını sağlayın

\section{Ulusal Meslek Derneklerinin Rolü}

- Mesleklerin katkısını en üst düzeye çıkarmak için ve sağlık profesyonellerinin optimal bir düzeyde çalışabilmesi için kendilerini destekleyen etkin sağık politikalarının oluşturulmasını sağlayın

- Sistemin her kademesinde sağllk profesyonellerinin katkısının en yüksek düzeyde olması için sağlık alanındaki meslek liderlerini destekleyin

\section{SONUÇ}

Sürdürülebilir Kalkınma Hedeflerinde belirtilen amaca ulaşmak için gelecekte yaşanacak zorlukların üstesinden gelebilme kapasitesine sahip, güçlü sağllk sistemleri oluşturmak için birlikte çalışmamız gerektiği açıkça ortadadır.

İhtiyacı olan tüm insanlara kaliteli sağlik hizmetlerini sağlamak hemşirelerin mesleki ve etik bir sorumluluğudur. Adanmış, yenilikçi ve çözüm odaklı profesyoneller olarak hemşireler, çok az durumda olan veya hiç olmayan kaynaklar ve organizasyonel destek ile bile ellerinden her iş gelerek sağlık hizmetini sunmaya devamediyorlar. Ancak sağlıksistemlerininzorlukların üstesinden gelebilme kapasitelerini geliştirmek bütün sektörlerin tüm kademelerini içeren şekilde sektörler arası çabayı gerektiriyor. Sağlık hizmetlerinin büyük bir bölümünü hem sağllk sektörü hem de bu sektörün dışındaki meslektașları ile iș birliği yaparak insanlara ulaştıran hemşireler bu süreçte önemli bir role sahiptir.

Hemşirelerin sağlık sektörü politikalarının reformunda yer alması gerektiğinin başka bir nedeni de bu politikaların hemşirelerin çalışma ortamı üzerinde sahip olduğu büyük etkidir. Sağlık sistemlerinin güçlendirilmesine dair alınan kararlara müdahil olarak, sağlık sistemlerinin gelişmiş bir zorlukların üstesinden gelme kapasitesi ve daha iyi sağlık sonuçları sağlayacak pozitif çalışma ortamlarını oluşturabiliriz.

Hemşireler değişime öncülük etmede tamamlayıcı bir rol oynamalıar. Yeniden yapılandırımış sağlık sistemleri ve sağlık sistemine dair bütün kararlarda hemşirelerin yer alması ile zorluk zamanlarında bile kaliteli sağllk hizmetini sunabilmek için daha iyi ekipmanlar ile donatımış olacağız.

\section{KAYNAKLAR}

1. World Health Organization. Health-system resilience: reflections on the Ebola crisis in western Africa.by Kieny MP, Evans DB, Schmets G, Kadandale S. Bull World Health Organ 2014; 92:850. http:// www.who.int/bulletin/volumes/92/12/14-149278/en/\#).

2. World Health Organization Health. Workforce density per 1000 population, Global Health Observatory data repository. (2015a). Available at: http://apps.who.int/gho/data/node.main. A1444?lang=en).

3. T.C. Sağlık Bakanlığı Halk Sağlığı Genel Müdürlüğü. "Covıd-19 (Sars-Cov-2 Enfeksiyonu) Rehberi”. https://covid19bilgi.saglik.gov. tr/depo/rehberler/COVID-19_Rehberi.pdf. Son Erişim Tarihi: 30 Nisan 2020.

4. World Health Organization. Health in 2015: from MDGs to SDGs. 2015b: Geneva: WHO. Available at www.who.int/gho/publications/ mdgs-sdgs/en/.

5. World Health Organization and World Bank. Tracking universal health coverage: First global monitoring report, 2015c: Joint WHO/ World Bank Group report.

6. David KE, Goldstein M, Popova A. Health-care worker mortality and the legacy of the Ebola epidemic. Lancet Global Health 2015;3: e439-e440.

7. World Health Organization. "Report of the WHO-China Joint Mission on Coronavirus Disease 2019 (COVID-19)". 2020: https:// www.who.int/docs/default-source/coronaviruse/who-china-jointmission-on-covid-19-final-report.pdf. Son Erişim Tarihi: 30 April 2020.

8. Istituto Superiore di Sanità. "Integrated surveillance of COVID-19 in Italy". 2020: https://www.epicentro.iss.it/en/coronavirus/bollettino/ Infografica_10aprile\%20ENG.pdf. Son Erişim Tarihi: 15 Mayıs 2020

9. Lai J, Ma S, Wang Y, Cai Z, Hu J, We N, et al. Factors associated with mental health outcomes among health care workers exposed to coronavirus disease 2019. JAMA 2020:3: 1-12.

10. Ran L, Chen X, Wang Y, Wu W, Zhang L, Tan X. Risk factors of healthcare workers with corona virus disease 2019: A retrospective cohort study in a designated hospital of Wuhan in China. Clinical Infectious Diseases 2020. March 17. Doi: https://doi.org/10.1093/ $\mathrm{cid} / \mathrm{ciaa287.}$

11. World Health Organization. Coronavirus disease (COVID-19) outbreak: rights,roles and responsibilities of health workers, including key considerations for occupational safety and health. 2020. https://www.who.int/publications-detail/coronavirusdisease-(covid-19)-outbreak-rights-roles-and-responsibilities-ofhealth-workers-including-key-considerations-for-occupationalsafety-and-health. Son Erişim Tarihi: 30 April 2020.

12. Campbell J, Cometto G, Rasanathan K, Kelley E, Syed S ,Zurn P, et al. Improving the resilience and workforce of health systems for women's, children's, and adolescents' health. BMJ 2015;351:h4148

13. Baumann A (2007). International Council of Nurses (ICN) positive practice environments: Quality workplaces = quality patient care, information and action tool kit [Electronic version]. from http:// www.icn.ch/indkit2007.pdf.

14. Kruk ME, Myers M, Varpilah T, Dahn BT. What is a resilient health system? Lessons from Ebola. Lancet 2015;385: 1910-2.

15. International Council of Nurses. Position statement: Participation of nurses I health services decision making and policy development, 2008. Available at: www.icn.ch/images/stories/documents/ 
publications/position_statements/D04_Participation_Decision_ Making_Policy_Development.pdf. Accessed 10 April 2020

16. Jameson DT, Summers LH, Alleyne G, Arrow KJ, Berkley S, et al, Yamey G. Global health 2035: a world converging within a generation, The Lancet 2013;382:1898 - 955.

17. Global Health Workforce Alliance. Synthesis paper of the thematic working groups. Towards a global strategy on human resources for health. 2015. Available at: www.who.int/hrh/documents/ synthesis_paper_them2015/en/).

18. Buchan J, Aiken L Solving nursing shortages: a common priority. J Clin Nurs 2008;17:3262-8.

19. Dick J, Clarke M, Van Zyl H, Daniels K. Primary health care nurses implement and evaluate a community outreach approach to health care in the South African agricultural sector. Int Nurs Rev 2007; 54:383-90.

20. Canadian Nurses Association. Ethics in Practice Social Justice in Practice. April 2009.

21. Sheridan NF, Kenealy TW, Connolly MJ, Mahony F, Barber PA, Boyd MA, et al. Health equity in the New Zealand health care system: a national survey. Int J for Equity Health 2011;10: 1-14.

22. International Council of Nurses. Closing the Gap: Increasing Access and Equity. International Nurses Day toolkit 2011. Available at:www.icn.ch/publications/2011-closing-the-gap-increasingaccess-andequity/. Accessed: 10 February 2020

23. Panter-Brick C. Health, Risk, and Resilience: Interdisciplinary Concepts and Applications. Annu Rev Anthropol 2014; 43:431-48.

24. McAlister M, McKinnon J. The importance of teaching and learning resilience in the health disciplines: A critical review of the literature. Nurse Educ Today 2009; 29:371-9.

25. NHS Direct. Healthcare risk assessment made easy. (2007). Available at: www.nrls.npsa.nhs.uk/resources/?Entryld45=59825. Accessed 18 April 2020

26. World Health Organization. Primary Health Care. Now More than Ever. (2008). Retrieved from: http://www.who.int/whr/2008/en/

27. Institute of Health Equity. Working for Health Equity: The Role of Health Professionals (2013). Available at: www. instituteofhealthequity.org/projects/working-for-health-equity-therole-of-healthprofessionals. Accessed 30 March 2020

28. International Council of Nurses. International Council of Nurses Statement on the joint ICN-WHO consultation on Global Strategy on Human Resources for Health (2015). Accessed 23 March 2020.

29. Oxfam (2015). Never Again Building resilient health systems and learning from the Ebola Crisis, 203, Briefing paper.
30. Sull A, Harland N, Moore A. Resilience of health-care workers in the UK; a cross-sectional survey. J Occup Med Toxicol 201;10:20.

31. Department of Health. NHS Health and Wellbeing Review, (2009). Leeds, UK.

32. Robertson I, Cooper C. Well-being: Productivity and happiness at work. (2011). UK: Palgrave Macmillan.

33. Robertson I, Cooper CL. Resilience. Stress Health 2013; 29:175-6.

34. Jackson D, Firtko A, Edenborough M. Personal resilience as a strategy for surviving and thriving in the face of workplace adversity: A literature review. J Ad Nurs 2007; 60:1-9 .

35. McDavid D. Mental health: A key challenge for Europe in the 21st century. Eurohealth 2013; 19: 14-7

36. Shamian J. Global voice, strategic leadership and policy impact: global citizens, global nursing. J.Int Nurs Rev 2015; 62:4.

37. Wilson S, Langford K. 10 ideas for 21st century healthcare. Innovation Unit London 2015. Available at: www.innovationunit. org/sites/default/files/DIGITAL\%20VERSION10\%20Ideas\%20 Final.pdf

38. Cooper A. Paperless In the United Kingdom. American Nurses Today. Special Issue 2013;8: 11.

39. Duffield CM, Diers D, O'Brien Pallas L, Aisbett C, Roche MA, King MT, et al. Nursing staffing, nursing workload, the work environment and patient outcomes. Appl Nurs Res 2011;24: 244-55.

40. Benton D. Advocating Globally to Shape Policy and Strengthen Nursing's Influence. Online J Issues Nurs 2012;17:5.

41. Sullivan M, Kiovksy RD, Mason DJ, Hill CD, Dukes C. Interprofessional collaboration and education. Am J Nurs 2015; 115: 47-54.

42. Tangcharoensathien V, Mills A, Palu T. Accelerating health equity: the key role of universal health coverage in the Sustainable Development Goals. BMC Med 2015; 13:101.

43. Fillingham D, Weir B. Systems leadership, Kings Fund, London 2014.

44. Fineberg HV A successful and sustainable health system-how to get there from here. N Engl J Med 2012;366:1020-7.

45. World Health Organization (2015d). Realizing Nurses' Full Potential, Bulletin of the World Health Organization, 93 (9): News. Available at: www.who.int/bulletin/volumes/93/9/en/ Accessed: 21 April 2020.

46. Jackson D, Firtko A, Edenborough M. Personal resilience as a strategy for surviving and thriving in the face of workplace adversity: A literature review. J Adv Nurs 2007; 60; 1-9.

47. NHS Leadership Academy. Systems leadership. (2015). Available at: www.leadershipacademy.nhs.uk/about/systems-leadership/. Accessed: 30 March 2020 